\title{
Leaching of manganese ore with aqueous sulphur dioxide solutions
}

\author{
PRAFULLA R RAISONI and SHARAD G DIXIT \\ Department of Chemical Technology, University of Bombay, Matunga, Bombay 400019 , \\ India \\ Abstract. Manganese can be easily leached from chemically inert manganese ore by \\ aqueous solutions of $\mathrm{SO}_{2}$. Total manganese dissolution occurs at $650 \mathrm{rpm}, 0.2 \%$ solid, \\ $426 \mu \mathrm{m}, \mathrm{pH}=1$ and $310 \mathrm{~K}$ in only $68 \mathrm{~min}$. The rate data for manganese fits the equation: \\ $1-\frac{2}{3} \alpha-(1-\alpha)^{2 / 3}=k t$. Diffusion through the siliceous layer appears to be rate-controlling. \\ Keywords. Manganese leaching: manganese dissolution.
}

\section{Introduction}

During the past few years, study of dilute solutions of sulphur dioxide as a leaching agent has attracted the attention of several researchers. This is especially true in the case of sea-bed nodules. The reaction between metal oxide and sulphur dioxide has been studied in detail by Miller and Wan (1983), Khalafalla and Pohlman (1981), and Raisoni and Dixit (1987). It has been observed that (i) the sulphurous acid leaching method is rapid, effective and sensitive (the entire dissolution reaction completed in only $8-10 \mathrm{~min}$ ). (ii) Dissolution takes place at ambient temperature and pressure. (iii) Sulphur dioxide is a waste gas. It is believed that about $10^{9}$ million tonnes of $\mathrm{SO}_{2}$ per year are added to the global environment. Thus, by utilizing $\mathrm{SO}_{2}$ as a leaching agent, air pollution can be minimized. (iv) The aqueous $\mathrm{SO}_{2}$ solution (lixiviant) offers highly reducing and highly oxidizing conditions with oxygen (Dixit and Raisoni 1987). Therefore, these leachants may be used to leach out valuable metals from minerals, ores and concentrates as primary sources while anodic slimes, flue dust, electronic scraps, alloys, filaments of the electric bulbs etc are other polymetallic secondary sources.

In this paper we report the results of the leaching of $\mathrm{Mn}$ from $\mathrm{Mn}$-ore which has been reported to be highly non-reactive towards $\mathrm{H}_{2} \mathrm{SO}_{4}$ leaching. This is a typical case where the capability of aqueous solutions of $\mathrm{SO}_{2}$ as a leaching agent is demonstrated. In particular, the effect of process conditions and kinetic factors affecting the rate have been investigated.

\section{Materials and methods}

\subsection{Materials}

Goa Mn-ore (M/s Electrolytic Manganese Limited, Thane, India), a highly inert ore to $\mathrm{H}_{2} \mathrm{SO}_{4}$ leaching was used. It contained $51.91 \% \mathrm{Mn}$ as estimated by the EDTA method. $\mathrm{SO}_{2}$ gas (M/s Star Freez, Bombay, India) was used as such. The total $\mathrm{SO}_{2}$ concentration was determined by the iodometric method. 


\subsection{Leaching experiment}

Leaching experiments were carried out in a one-litre cylindrical glass reactor, immersed in a thermostatically controlled water bath. The upper lid had three openings through which a stirrer, a fritted solution sampler and a gas sparger were introduced into the glass reactor. Experiments were generally carried out at $0.2 \%$ solid of size $426 \mu \mathrm{m}, 650 \mathrm{rpm}, \mathrm{pH}=1$ and $310 \mathrm{~K}$ (unless reported otherwise). $\mathrm{SO}_{2}$ gas was bubbled through a solvent $\left(\mathrm{H}_{2} \mathrm{O}, 500 \mathrm{ml}\right)$ to attain $\mathrm{pH}=2$ and the total $\mathrm{SO}_{2}$ concentration was determined iodometrically. $\mathrm{pH}$ was adjusted using $\mathrm{AR}$ grade $\mathrm{H}_{2} \mathrm{SO}_{4}$. The dissolution reaction was initiated by adding the required amount of solid $(0.2 \%)$ to the reactor. The sample was withdrawn at regular intervals for analysis. The total Mn content was estimated by the EDTA method.

\section{Experimental results and discussion}

Leaching of $\mathrm{Mn}$ from Mn-ore (which was difficult to dissolve) by aqueous solutions of $\mathrm{SO}_{2}$ was carried out to study the effect of different parameters such as stirring speed, particle size, concentration of $\mathrm{SO}_{2}$ and temperature.

\subsection{Effect of stirring speed}

The ratio of solid to liquid was deliberately kept low to ensure a constant bulk solution concentration. The speed of rotation was varied from $250-850 \mathrm{rpm}$. The results in figure 1 reveal that the fraction of $\mathrm{Mn}$ extracted (in $5 \mathrm{~min}$ ) increases up to $650 \mathrm{rpm}$. However, a further increase in $\mathrm{rpm}$ did not show any effect on the extraction. Therefore, a speed of $650 \mathrm{rpm}$ was fixed for the rest of the experiments.

\subsection{Effect of particle size}

The effect of particle size was studied by taking the following size fractions: 1900,855 ,

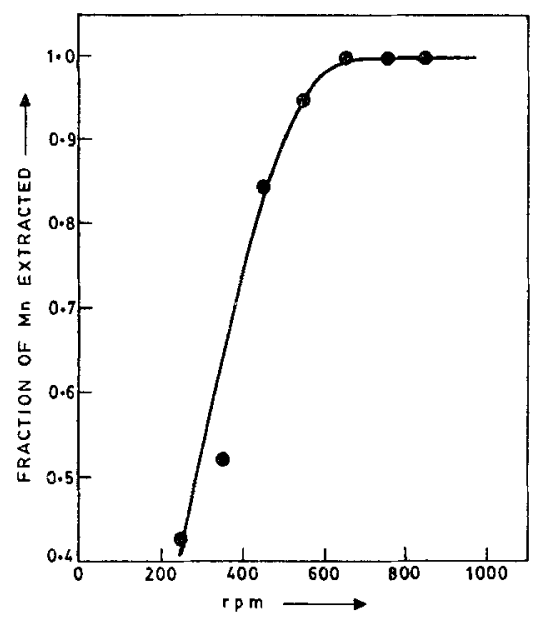

Figure 1. Effect of stirring speed on Mn extraction. 
$605,426,301$ and $152 \mu \mathrm{m}$. The fraction of $\mathrm{Mn}$ extracted against time (figure 2 ) shows that, as the particle size decreases, the rate of $\mathrm{Mn}$ dissolution increases. However, beyond $426 \mu \mathrm{m}$, the particle size had no effect on $\mathrm{MnO}_{2}$ dissolution, which was completed in only $8 \mathrm{~min}$. Thus, fine grinding of sample is not necessary and this helps in keeping down the costs.

\subsection{Effect of $\mathrm{SO}_{2}$ concentration}

The effect of $\mathrm{SO}_{2}$ concentration on the $\mathrm{MnO}_{2}$ dissolution was studied at $0 \cdot 2 \%$ solid, $426 \mu \mathrm{m}, 650 \mathrm{rpm}$ and $310 \mathrm{~K}$. The concentration was varied from 0.2 to $0.68 \mathrm{M}$. The results shown in figure 3 indicate that as concentration increases, the initial rate (in $2 \mathrm{~min}$ ) of $\mathrm{Mn}$ dissolution also increases but the overall reaction was complete in only 8 min. Thus, the total manganese leached depended on the total amount of $\mathrm{SO}_{2}$ in water, and not on $\mathrm{SO}_{2}$ concentration.

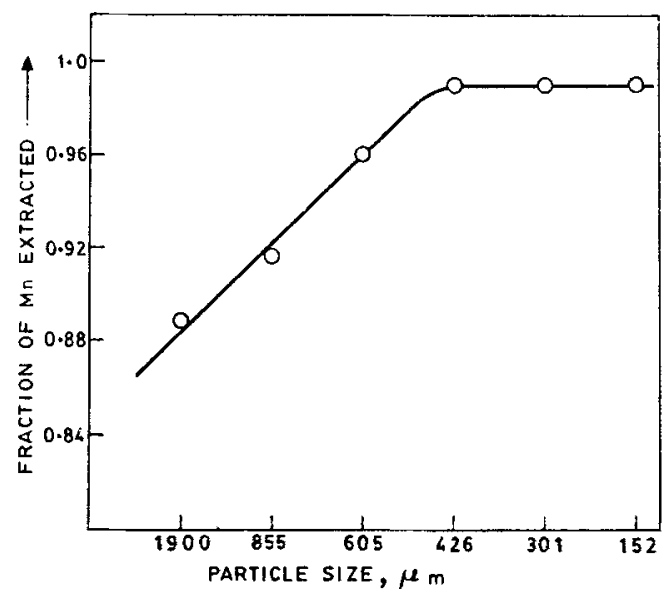

Figure 2. Effect of particle size on Mn extraction.

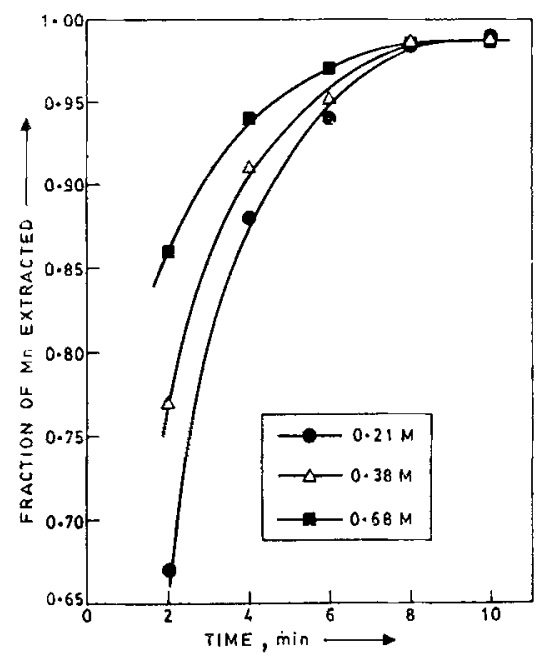

Figure 3. Effect of $\mathrm{SO}_{2}$ concentration on Mn extraction. 


\subsection{Effect of temperature}

Leaching of $\mathrm{Mn}$ from $\mathrm{Mn}$-ore was studied by varying the temperature from $270 \cdot 5$ $310 \mathrm{~K}$ at $0.2 \%$ solid, $650 \mathrm{rpm}, \mathrm{pH}=1,426 \mu \mathrm{m}$. The results (figure 4 ) show that as the temperature increases $(270.5-310 \mathrm{~K})$, the dissolution rate of $\mathrm{Mn}$ also increases. However, a further rise in temperature $(320 \mathrm{~K})$ resulted in slight decrease in the dissolution of $\mathrm{Mn}$ (not shown in figure 4). This is due to the decrease in $\mathrm{SO}_{2}$ concentration in water. Thus, manganese can be easily leached out from chemically inert $\mathrm{Mn}$-ore at $0 \cdot 2 \%$ solid, $\mathrm{pH}=1,426 \mu \mathrm{m}$ and $310 \mathrm{~K}$. The entire dissolution is completed within $8-10 \mathrm{~min}$.

\subsection{Kinetics of dissolution}

Miller and Wan (1983) demonstrated conclusively that the overall kinetics of dissolution of electrolytic manganese dioxide (EMD) in aqueous solutions of $\mathrm{SO}_{2}$ is controlled by the electrochemical reaction at the interface. Thus, the following equation is expected to hold

$$
1-(1-\alpha)^{1 / 3}=k t
$$

where $\alpha$ is the fraction of $\mathrm{Mn}$ extracted, $k$ the constant and $t$ is time in minutes.

However, when the experimental data were plotted according to the above equation, straight lines were not obtained. Alternatively, the following diffusion equation applies:

$$
\mathrm{d} n(\mathrm{Mn}) / \mathrm{d} t=\left(-4 \pi r^{2} / \sigma\right) D(\mathrm{~d} C / \mathrm{d} r)
$$

where $r$ is the radius of the unreacted particle, $n$ is the number of the solution, $C$ the bulk solution concentration, $D$ the effective diffusion coefficient and $\sigma$ the stoichiometry factor.

The above equation may be integrated, assuming the constancy of $C$. Ginstling and Brounshetein (1950) have given a solution of the above equation assuming the constancy of $C$ as follows,

$$
1-\frac{2}{3} \alpha-(1-\alpha)^{2 / 3}=2 V D C / \sigma r_{0}^{2}
$$

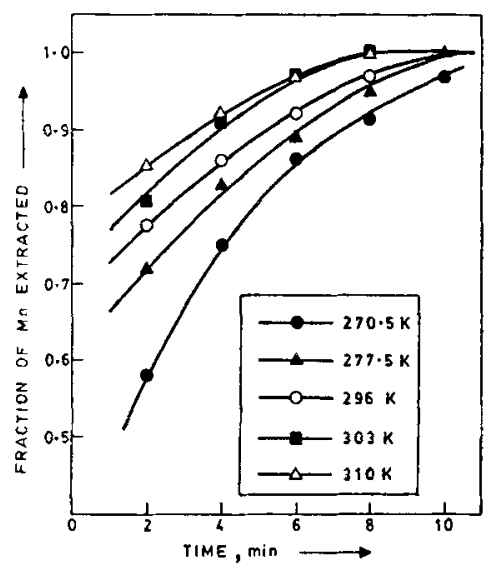

Figure 4. Effect of temperature on $\mathrm{Mn}$ extraction. 


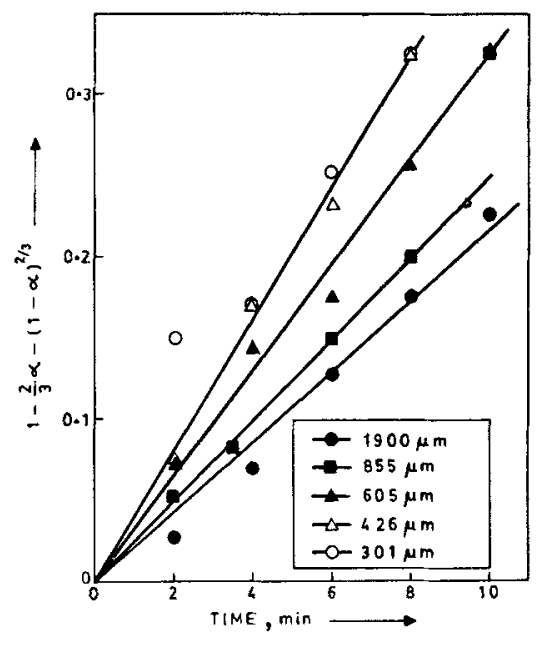

Figure 5. Plot of $1-(2 / 3) \alpha-(1-\alpha)^{2 / 3}$ against time for various particle sizes.

where $V$ is the volume of the solution. In the present case the constancy of $C$ is assured because the solid concentration has been taken as very low $(0 \cdot 2 \%)$.

The experimental data have been plotted in figure 5 to test the validity of equation (3). Excellent straight lines passing through the origin have been obtained. Thus the rate of $\mathrm{Mn}$ dissolution is controlled by diffusion. In the present case, diffusion through the unreacted siliceous layer is possible and the validity of (3) indicates that it is rate-controlling.

The above results also clear the fact that the kinetic factors for the pure material (in this case the electrolytic manganese dioxide) and the ore could be entirely different.

\section{Conclusions}

$\mathrm{H}_{2} \mathrm{SO}_{3}$ leaching is a rapid, effective and sensitive method compared to $\mathrm{H}_{2} \mathrm{SO}_{4}$ leaching. Reactions can be carried out at an ambient temperature and pressure within 8-10 min, while several days are required for mineral acid leaching. Total Mn dissolution from $\mathrm{Mn}$-ore is possible in only $8 \mathrm{~min}$ and diffusion through silica layer controls the reaction rate.

\section{Acknowledgement}

This work was funded by CSIR, New Delhi.

\section{References}

Crank J 1957 Trans. Faraday Soc. 531083

Dixit S G and Raisoni P R 1987 Ind. J. Tech. 25517

Ginstling A M and Brounshetein B I $1950 \mathrm{~J}$. Appl. Chem. USSR (English transl.) 231327

Khalafalia S E and Pohlman J E 1981 US B.M.R.I $\$ 518$

Miller J D and Wan R Y 1983 Hydrometallurgy 10219

Raisoni P R and Dixit S G 1987 Minerals engineering (in Press) 